\title{
Public and Private Investment in the Port Sector in Mexico, 2000-2010: A Study Through Data Envelopment Analysis
}

\author{
Odette V. Delfín-Ortega, César L. Navarro-Chávez \\ Universidad Michoacana de San Nicolás de Hidalgo, Morelia Michoacán, México
}

\begin{abstract}
Knowing the level of efficiency of investment applied in ports of Mexico is relevant information for the design of port policies that contribute to its development and thus to greater freight movement. The objective of this paper is to analyze the technical efficiency obtained from International Mexican Ports, through the use of the technique of Data Envelopment Analysis (DEA). It uses data regarding public and private investment in ports applied during the period 2000-2010 and its influence on the number of Twenty-foot Equivalent Unit (TEU). Because it has been applied the DEA-CCR (the linear programming model) model input oriented, thus not only the efficiency is calculated in ports, but benchmarking is also obtained to determine the efficient ports that serve as reference to those who were found to be inefficient. The results obtained showed that Manzanillo and Progreso were the most efficient ports. On the other hand, the ports that were not efficient for any of the years reviewed were Mazatlan and Lazaro Cardenas. Generally, public investment has been increasing over the period, and public policies are not designed to allow the ports to have an international projection.
\end{abstract}

Keywords: ports, investment, Data Envelopment Analysis (DEA), technical efficiency

\section{Introduction}

The ports are a representative part in the development of a country, allowing a more efficient transport system. However, not all ports have optimal development to face the challenges in three main areas: industry, commerce, and tourism (SCT, 2008).

Since a central theme is investment in port policies, this research aims to determine the levels of efficiency of public and private investment in the port sector in Mexico during the period 2000 to 2010. It is important because at the end of 2010, investment in ports was 49.801 million pesos, of which 25.981 million pesos correspond to public investment and 19.820 million pesos correspond to private investment (SCT, 2011) and in the same year 4,223,631 TEUs moved in Mexican ports (CGPMM, 2011). If compared these numbers with those obtained in 2,000 where it was moved 1,315,749 TEUs, it got a growth of $221 \%$.

This paper addresses the problem of measurement using a model called DEA. It is a nonparametric method for estimating production frontiers and efficiency assessment of a sample of production units (DMUs or

Odette V. Delfín-Ortega, Ph.D., Institute of Economic and Business Research, Universidad Michoacana de San Nicolás de Hidalgo.

César L. Navarro-Chávez, Ph.D., Institute of Economic and Business Research, Universidad Michoacana de San Nicolás de Hidalgo.

Correspondence concerning this article should be addressed to Odette V. Delfín-Ortega, calle 8 de mayo no. 269 Lomas de Hidalgo Morelia Michoacán, 58000, México. E-mail: odettedelfin@hotmail.com. 
decision making units). The port production structure is determined by the inputs; in this case they are: public investment and private investment. To achieve the result (output) is to mobilize the largest number of containers at ports.

The importance of this analysis is that, in most ports, activities in the past were operated entirely by the state and that in the last two decades they have been restructuring the pattern of private investment in order to balance the provision of public service, commercial development, and increased freight movement. For this reason, the hypothesis of this research is: Mexican ports have failed to be more efficient with private investment.

\section{Literature Review}

Farrell (1957) was the first author to introduce a quantitative approach to efficiency, proposing a measurement in which each decision unit may be assessed in relation to other homogeneous units, so that efficiency becomes a relative concept and not an absolute one, where the value taken by the efficiency for each entity indicates the observed deviation regarding those considered as efficient.

DEA model is a nonparametric technique that facilitates the construction of an enveloping surface or efficient frontier from the available data set under study, entities known as DMU (Decision Making Unit) (Charnes, Cooper, \& Rhodes, 1978), in which each of these DMUs gets a weight or value of the inputs and outputs which maximize the efficiency value of the production. Thus inefficient units are outside of the border, allowing one to evaluate the relative efficiency on each of the units.

The literature on technical efficiency has its origin in the early years of the decade of the 1950s. The first formal definition of technical efficiency comes from Koopmans (1951) who wrote that it "is one in which an increase in any of the outputs requires a reduction in at least one of the remaining or the increase of any of the inputs”, and the first measure of technical efficiency is given by Debreu (1951) and Shephard (1953), although with different orientation (output and input, respectively). Despite the theoretical relevance of these studies, none of them quantified efficiency.

By efficiency, it means the comparison between observed and optimal inputs and outputs. The comparison can be through:

- A comparison of the maximum attainable output for a given level of inputs, and that actually achieved (outputs orientation);

- A comparison of the minimum level of inputs required for a given level of outputs, and the level actually achieved (orientation inputs).

The work of Farrell is complemented by the works of Charnes et al. (1978) that were based on constant returns to scale (CRS), so that a change in the level of inputs leads to a proportional change in the level of output, which requires as many optimizations as DMU from the CCR as follows:

$$
\begin{aligned}
& \operatorname{Max} \sum_{k=1}^{s} V_{k} Y_{k p} \\
& \text { s.t } \sum_{j=1}^{m} U_{j} X_{j p}=1 \\
& \sum_{k=1}^{s} V_{k} Y_{k i}-\sum_{j=1}^{m} U_{j} X_{j 1} \leq 0 \quad \forall i
\end{aligned}
$$




$$
V_{k}, U_{j} \geq 0 \quad \forall k, j
$$

Later, Banker, Charnes, and Cooper (1984) extended the original model to include VRS and the model (BCC):

$$
\begin{gathered}
\text { Min } \theta_{\kappa} \\
\chi_{i \kappa}-\sum_{l=1}^{n} \lambda_{l} X_{i l} \geq=0, \quad i=1,2, \ldots, M \\
\sum_{l=1}^{n} \lambda_{l} Y_{i l} \geq=Y j k^{\prime} \quad j=1,2, \ldots, S \\
\sum_{l=1}^{n} \lambda_{l}=1
\end{gathered}
$$

\section{Port Sector Efficiency Through DEA}

Martínez-Budría, Díaz-Armas, Navarro-Ibáñez, and Ravelo-Mesa (1999) analyzed the efficiency of 26 Spanish port services during the 1993-1997 period. They used the DEA-BCC model and divided the sample into three groups namely: high complexity ports, medium complexity ports, and small complexity ports. Results obtained show that "high complexity ports" had the best efficiency.

On the other hand, Park and De (2004) realized an analysis of port efficiency using the DEA-CCR model and DEA-BCC model in Korean ports. The study finds that alternative DEA is a potentially powerful approach to the evaluation of the overall efficiency of seaports. Cullinane, Song, and Wang (2005) studied the technical efficiency of port container terminal, using the DEA model, CCR model, and DEA-BCC model too. The paper presents the pros and cons of port privatization and provides an empirical examination of the relationship between privatization and relative efficiency within the container port industry.

González and Trujillo (2008) realized a study of technical efficiency in port infrastructure service in Spanish ports. They analyzed the port reforms that took place in the 1990s and its impact on the efficiency. The results show that the reforms produce significant improvements in technological change, but that technical efficiency has in fact changed little on average.

Sala and Medal (2004) analyzed the efficiency of 28 Spanish ports using a non-radial DEA model: the Russell Measure. As a result of the analysis, they concluded that the Spanish Port System had generally a high average level of efficiency but it could grow around $20 \%$ to consider that all ports operate on the efficient frontier.

\section{Methodological Development}

In this research, it has applied the DEA-CCR model, which identifies the Global Technical Efficiency (GTE) of the units DMUs analyzed. The model proposed is oriented inputs, where optimization of inputs is reduced as much as possible to be more efficient. It analyses the capacity of the port to minimize investment applied considering a given level of outputs, so that the results of the DEA informs investment units which mostly could be applied to be efficient.

It begins by determining the sample which is subject to analysis of technical efficiency of major ports during 2000, 2005, and 2010. Selected DMUs are: Ensenada, Mazatlan, Manzanillo, Lazaro Cardenas, Salina Cruz, Puerto Morelos, Puerto Progreso, Veracruz, Tuxpan, Altamira, and Tampico. It took two selection 
criteria: They should be international ports and they have to have handled containerized cargo.

For the selection of inputs and outputs, it was revised several studies on port efficiency. It must consider that the main objective of this research is to determine the levels of efficiency of public and private investment in the port sector in Mexico during the period 2000-2010. This is the reason why it is making a discrimination of variables, based on the objective to be achieved. Finally it models a production function where there are two inputs: public and private investment and one output number of annual TEUs, and to check the correlation between the variables, it makes a Pearson Matrix where it could determine whether the inputs can explain the outputs.

For data that model the production function, several sources were used, including: the statistical yearbooks of ports in Mexico, in 2000, 2005, and 2010 in the section Container Movement Coordination of Ports and Merchant Marine, SCT, as well as each of the port development plans for selected periods.

\section{Results of Efficiency Through the DEA Model With CCR}

It is observed in Table 1 that in 2000, four of the 11 ports had been efficient in implementing the port investment, which were Manzanillo, Veracruz, Progreso, and Puerto Morelos since they obtained a coefficient of one, and the port of Salina Cruz was the least efficient. In 2005 the efficient ports were Manzanillo, Salina Cruz, Altamira, and Progreso, in the same year the least efficient port was Lazaro Cardenas. Finally in 2010 there were more efficient ports: Ensenada, Manzanillo, Tampico, Tuxpan, and Progreso and the least efficient was the port of Veracruz. Importantly, the port of Manzanillo and Progreso was the most efficient in the three years analyzed.

Table 1

Technical Efficiency of Public and Private Investment in Mexico Ports, 2000-2010

\begin{tabular}{llll}
\hline DMU & 2000 & 2005 & 2010 \\
\hline Ensenada & 0.5661 & 0.7796 & 1 \\
Mazatlán & 0.2527 & 0.4422 & 0.4251 \\
Manzanillo & 1 & 1 & 1 \\
Lázaro Cárdenas & 0.7885 & 0.1155 & 0.192 \\
Salina Cruz & 0.2078 & 1 & 0.4755 \\
Altamira & 0.625 & 1 & 0.7356 \\
Tampico & 0.3504 & 0.379 & 1 \\
Tuxpan & 0.2147 & 0.5263 & 1 \\
Veracruz & 1 & 0.6355 & 0.0503 \\
Progreso & 1 & 1 & 1 \\
Pto Morelos & 1 & 0.3972 & 0.5026 \\
\hline
\end{tabular}

Note. Source: Personal compilation based on DEA results.

In Table 2, it can be seen that the behavior of public and private investment in ports shows that in 2000 there were six ports efficient in the implementation of private investment: Mazatlan, Manzanillo, Lazaro Cardenas, Salina Cruz, Tuxpan, and Progreso; on the other hand, four ports were efficient in the implementation of public investment for the same year: Altamira, Tampico, Veracruz, and Puerto Morelos.

In 2005, the number of ports that were efficient with private investment was reduced: Salina Cruz, Veracruz, and Progreso. In that same year, the ports that were efficient in implementing public investment increased to five: Ensenada, Altamira, Tampico, Tuxpan, and Puerto Morelos. 
Finally in 2010, again three ports were efficient in terms of private investment: Ensenada, Lazaro Cardenas, and Tampico. In the case of public investment, this time there were six efficient ports: Mazatlan, Salina Cruz, Altamira, Tuxpan, Veracruz, and Puerto Morelos. It is important to observe that the implementation of public investment has been increasing in the last decade, making double the number of efficient ports in 2010 compared to 2000 and specifically the ports of Altamira and Puerto Morelos have achieved optimal efficiency in the use of public investment during the three periods analyzed.

Table 2

Importance of Public and Private Investment in Technical Efficiency of the Ports in Mexico, 2000-2010

\begin{tabular}{lllllll}
\hline \multirow{2}{*}{ DMU } & \multicolumn{5}{l}{2005} & \multicolumn{3}{c}{2010} \\
\cline { 2 - 7 } & Public investment & Private investment & Public investment & Private investment & Public investment & Private investment \\
\hline Ensenada & 0.85 & 0.15 & 1 & 0 & 0 & 1 \\
Mazatlán & 0 & 1 & 0.96 & 0.04 & 1 & 0 \\
Manzanillo & 0 & 1 & 0.96 & 0.04 & 0.88 & 0.12 \\
Lázaro Card & 0 & 1 & 0.48 & 0.52 & 0 & 1 \\
Salina Cruz & 0 & 1 & 0 & 1 & 1 & 0 \\
Altamira & 1 & 0 & 1 & 0 & 1 & 0 \\
Tampico & 1 & 0 & 1 & 0 & 0 & 0 \\
Tuxpan & 0 & 1 & 1 & 0 & 1 & 0 \\
Veracruz & 1 & 0 & 0 & 1 & 1 & 0.39 \\
Progreso & 0 & 1 & 0 & 1 & 0.61 & 0 \\
Pto.Morelos, & 1 & 0 & 1 & 0 & 1 & 0
\end{tabular}

Note. Source: Personal compilation based on DEA results.

\section{Benchmarking Analysis}

With the Benchmarking analyses, it can identify which DMU can be considered as a reference for inefficient DMUs, having similar characteristics. Table 3 shows how in 2000, Puerto Morelos was the port that was taken as reference many times. In 2005, the ports that were taken more frequently as reference were Salina Cruz and Altamira and in the year 2010 the port that was taken as further reference regarding the other was Manzanillo.

Table 3

Benchmarking Analysis of the Port Sector in Mexico, 2000-2010

\begin{tabular}{llll}
\hline DMU & 2000 & 2005 & 2010 \\
\hline 1. Ensenada & $3(0.03) 10(0.19) 11(0.79)$ & $6(0.19) 10(0.21)$ & 7 \\
2. Mazatlán & $10(0.20) 11(0.80)$ & $10(0.24)$ & $1(0.01) 3(0.02)$ \\
3. Manzanillo & 3 & $6(1.74) 10(4.27)$ & 8 \\
4. Lázaro Cárdenas & $11(1.00)$ & $6(0.18) 10(1.04)$ & $1(0.53) 3(0.47)$ \\
5. Salina Cruz & $11(1.00)$ & $10(0.01)$ & $3(0.00)$ \\
6. Altamira & $3(0.42) 11(0.58)$ & 6 & $1(0.10) 3(0.31)$ \\
7. Tampico & $3(0.10) 11(0.90)$ & $6(0.01) 10(0.10)$ & $1(0.01)$ \\
8. Tuxpan & $11(1.00)$ & $10(0.00)$ & $1(0.00) 3(0.00)$ \\
9. Veracruz & 0 & $6(0.82) 10(4.93)$ & $1(0.00) 3(0.00)$ \\
10. Progreso & 2 & 9 & $1(0.25) 3(0.01)$ \\
11. Puerto Morelos & 7 & $6(0.01) 10(0.08)$ & $3(0.00)$ \\
\hline
\end{tabular}

Note. Source: Personal compilation based on DEA results.

\section{Analysis Slacks}

In the analysis of the variables slacks, let us see where it may be necessary to reduce some additional 
factor or increased output. As seen in Table 4 in 2010, the port of Mazatlan required 65.89 million pesos decreases in private investment to be more efficient and increases the number of TEUs moved annually by 0.01 units. On the other hand, Lazaro Cardenas needs to decrease public investment by 0.11 million dollars and increase the number of TEUs handled by 0.01 units annually in order to be more efficient.

The ports of Salina Cruz, Altamira, Veracruz, and Puerto Morelos should reduce private investment by the amounts of 1,866 million, 39.72 million, 29.96 million, and 331.69 million pesos respectively to become more efficient.

Table 4

Slacks Variables Analysis, 2010

\begin{tabular}{llcc}
\hline \multirow{2}{*}{ DMUs } & Input & Output \\
\cline { 2 - 4 } & $\{\mathrm{S}\} \operatorname{Ipub}\{\mathrm{I}\}$ & $\{\mathrm{S}\}$ Ipriv $\{\mathrm{I}\}$ & $\{\mathrm{S}\}$ Teus $\{\mathrm{O}\}$ \\
\hline Ensenada & 0 & 65.89 & 0.01 \\
Mazatlán & & & 0.01 \\
Manzanillo & 0.11 & 1,866 & 0 \\
Lázaro Cárdenas & 0 & 39.72 & 0 \\
Salina Cruz & 0 & & \\
Altamira & & 29.96 & 0 \\
Tampico & 0 & & 0 \\
Tuxpan & & 331.69 & \\
Veracruz & 0 & & \\
Progreso & & & \\
Puerto Morelos & & & \\
\hline
\end{tabular}

Note. Source: Personal compilation based on DEA results.

\section{Discussion of Results}

This work is a pioneer effort in the analysis of port efficiency with the implementation of public and private investment in Mexico, as in reviewing the literature using DEA methodology. However, in this study it was observed that in the years 2000 and 2005, 64\% of the ports were inefficient and by 2010 the percentage of inefficient ports was 55\%. This situation shows even though the public and private investment is applied according to the growth strategies embodied in port development plans, how they have failed to produce the port development expected. Ports that were efficient throughout the period under review are: Manzanillo and Progreso.

Moreover the results show, the application of private investment, failed to produce more efficient ports, the number of efficient ports was declining over the period analyzed, starting in 2000 with six ports and in 2010 there were only three ports that showed efficient implementation of private investment. In the case of public investment, the behavior was the opposite of private investment as it began in 2000 with four efficient ports and in 2010 there were six ports which were shown to be efficient with the application of this resource. Puerto Morelos and Altamira are highlighted for ports that during the study period were more efficient with the implementation of public investment.

In the specific case of the port of Lazaro Cardenas, it failed to be effective in any of the periods analyzed and observed as in 2010 it should have been efficient with only 19.2\% of the inputs used, and the results of the slacks variables show that it had an excess of 0.11 million in investment applied. In the same direction 
benchmarking analysis indicated as reference ports Mazatlan and Manzanillo, which had similar characteristics in the use of their resources and in whether they were efficient.

\section{Conclusions}

The economic growth rate in Mexico, as well as the growth of public and private investments in ports has been insufficient to meet the needs of transport and communications of the population and to achieve internationally competitive standards. The importance of efficient ports is crucial, because it reduces transport costs and increases the commercial dynamism, as just over a third of the total charge of the country and most of the volume of exports including oil and derivatives are transported through the ports.

The model of DEA is a linear programming technique that facilitates the construction of an envelope surface or efficient frontier from the available data set under study entities called DMUs and allows us to analyze the level of port efficiency. In this research, the model used is DEA-CCR which is input oriented. Inputs are considered as public investment and private investment, and output is represented by the number of containers.

The results of the technical efficiency DEA-CCR during 2000 to 2010, were shown as the ports that were distinguished by having higher levels of efficiency in 2000 were Manzanillo, Veracruz, Progreso, and Puerto Morelos, in 2005 the most representative ports are: Manzanillo, Salina Cruz, Altamira and Progreso, and in 2010 they were Ensenada, Manzanillo, Tampico, Tuxpan, and Progreso. Highlighting Manzanillo and Progreso throughout the period, they were efficient. On the other hand, the ports that were not efficient for any of the years reviewed were Mazatlan and Lazaro Cardenas.

The DEA methodology allows benchmarking analysis and it identifies the ports that were taken as reference in the period 2000-2010, which are: Puerto Morelos, Salina Cruz, Altamira, and Manzanillo.

The main problems for passing ports to achieve the levels of efficiency in investment primarily have to do with the implementation of private investment, as it decreased during the period 2000-2010 and the results obtained show ports that have failed to be more efficient with the contribution of private investment.

The ports of Mazatlan and Lazaro Cardenas, although they have invested in the growth of container terminals, are less efficient and also they have not increased the number of TEUs handled annually to have attained the projected potential, by rethinking what is missing in their port development plans and strategies to make them more competitive.

This type of study allows us to see the changes that occurred after the introduction of private investment, however for future research, it should be analyzed in detail, each item of the implementation of the investment and what was their impact on the port, not only in the international ports, but also in the rest of the ports.

Finally, although public investment has been increasing over the period, public policies are not designed to allow the ports to have an international projection, since shipping is evolving rapidly and the responsiveness and attention from the Mexican seaports are not growing at the same pace.

\section{References}

Banker, R., Charnes, A., \& Cooper, W. (1984). Some models for estimating technical and scale inefficiencies in data envelopment analysis. Management Science, 30(9), 1078-1092.

Charnes, A., Cooper, W., \& Rhodes, E. (1978). Measurement the efficiency of decision making units. European Journal of Operational Research, 2, 429-444.

Coordinación General de Puertos y Marina Mercante (CGPMM). (2011). Container movement: Statistical yearbook of the ports in Mexico, 2011. Retrieved from http://www.sct.gob.mx/fileadmin/CGPMM/U_DGP/estadisticas/2011/Anuarios/index.htm 
Cullinane, K., Song, D., \& Wang, T. (2005). The relationship between privatization and DEA estimates of efficiency in the container port industry. Journal of Economics \& Bussiness, 57, 433-462.

Debreu, G. (1951). The coefficient of resource utilization. Econometrica, 19(3), 273-292.

Farrell, M. (1957). The measurement of productive efficiency. Journal of the Royal Statistical Society, 120(3), 253-267.

González, M., \& Trujillo, L. (2008). Reforms and infrastructure efficiency in Spain’s container ports. Transportation Research, 42, 243-257.

Koopmans, T. (1951). Efficient allocation of resources. Econometrica, 19(4), 455-465.

Martínez-Budría, E., Díaz-Armas, R., Navarro-Ibáñez, M., \& Ravelo-Mesa, T. (1999). A study of the efficiency of Spanish port authorities using data envelopment analysis. International Journal of Transport Economics, XXVI (2), 237-253.

Park, R., \& De, P. (2004). An alternative approach to efficiency measurement of seaports. Maritime Economics \& Logistics, 6(1), 53-69.

Sala, R., \& Medal, A. (2004). Study of the technical and economic efficiency of container terminals (pp. 1-11). Department of Mathematical Economics and Business Department of Business Finance. University of Valencia.

Shephard, R. (1953). Cost and production functions. Princeton: Princeton University Press.

Transport and Communications Sector (SCT). (2008). National port development program, current status of the national port system. Retrieved from http://cgpmm.sct.gob.mx/fileadmin/PNDP2008/htm/pndp.htm

Transport and Communications Sector (SCT). (2011). Statistics communications and transport sector: Planning general leadership. Retrieved

from

http://www.sct.gob.mx/informacion-general/planeacion/estadistica-del-sector/indicadores-mensuales-sct/2011/ 